\title{
Associations between proinflammatory cytokines in the synovial fluid and radiographic grading and pain-related scores in 47 consecutive patients with osteoarthritis of the knee
}

Sumihisa Orita ${ }^{1,4^{*}}$, Takana Koshi ${ }^{2}$, Takeshi Mitsuka ${ }^{3}$, Masayuki Miyagi ${ }^{4}$, Gen Inoue ${ }^{4}$, Gen Arai ${ }^{4}$, Tetsuhiro Ishikawa ${ }^{4}$, Eiji Hanaoka ${ }^{5}$, Keishi Yamashita ${ }^{3}$, Masaomi Yamashita ${ }^{3}$, Yawara Eguchi ${ }^{4}$, Tomoaki Toyone $^{6}$, Kazuhisa Takahashi $^{4}$ and Seiji Ohtori ${ }^{4}$

\begin{abstract}
Background: One of the sources of knee pain in osteoarthritis $(\mathrm{OA})$ is believed to be related to local chronic inflammation of the knee joints, which involves the production of inflammatory cytokines such as tumor necrosis factor alpha (TNF $\alpha$ ), interleukin (IL)-6, and nerve growth factor (NGF) in the synovial membrane, and these cytokines are believed to promote pathological OA. In the present study, correlations between proinflammatory cytokines in knee synovial fluid and radiographic changes and functional scores and pain scores among OA patients were examined.

Methods: Synovial fluid was harvested from the knees of 47 consecutive OA patients, and the levels of TNF $\alpha, \mathrm{IL}-6$, and NGF were measured using enzyme-linked immunosorbent assays. Osteoarthritic knees were classified using Kellgren-Lawrence (KL) grading (1-4). The Western Ontario and McMaster University Osteoarthritis Index (WOMAC) was used to assess self-reported physical function, pain, and stiffness.

Results: TNF $\alpha$ and IL-6 were detectable in knee synovial, whereas NGF was not. TNF $\alpha$ was not correlated with the $\mathrm{KL}$ grade, whereas IL-6 had a significantly negative correlation. We observed differences in the correlations between TNF $\alpha$ and IL-6 with WOMAC scores and their subscales (pain, stiffness, and physical function). TNF $\alpha$ exhibited a significant correlation with the total score and its 3 subscales, whereas IL-6 exhibited a moderately significant negative correlation only with the subscale of stiffness.

Conclusions: The present study demonstrated that the concentrations of proinflammatory cytokines are correlated with $\mathrm{KL}$ grades and WOMAC scores in patients with knee OA. Although TNFa did not have a significant correlation with the radiographic grading, it was significantly associated with the WOMAC score. IL-6 had a significant negative correlation with the $\mathrm{KL}$ grading, whereas it had only a weakly significant correlation with the subscore of stiffness. The results suggest that these cytokines play a role in the pathogenesis of synovitis in osteoarthritic knees in different ways: TNF $\alpha$ is correlated with pain, whereas IL-6 is correlated with joint function.
\end{abstract}

\section{Background}

Knee osteoarthritis (OA) is a common chronic degenerative disease characterized by the loss of articular cartilage components due to an imbalance between extracellular matrix destruction and repair [1]. The entire joint structure is affected, including the synovial

\footnotetext{
* Correspondence: sumihisa@silver.email.ne.jp

'Department of Orthopaedic Surgery, Chiba Rosai Hospital, Chiba, Japan Full list of author information is available at the end of the article
}

membrane and subchondral bone, and OA can be recognized as an irregularity and deformity of joint spaces in radiographic images. Its main clinical sign is joint pain, which not only contributes to functional limitations and reduced quality of life but is also the leading cause of impaired mobility in the elderly population [2]. Although the exact mechanism of knee pain in OA is unclear, it is believed to be related to local chronic inflammation of the knee joints, which involves the
C Biomed Central

(c) 2011 Orita et al; licensee BioMed Central Ltd. This is an Open Access article distributed under the terms of the Creative Commons Attribution License (http://creativecommons.org/licenses/by/2.0), which permits unrestricted use, distribution, and reproduction in any medium, provided the original work is properly cited. 
production of inflammatory cytokines in the synovial membrane, such as tumor necrosis factor alpha (TNF $\alpha$ ), interleukin (IL)-6, and nerve growth factor (NGF), which are generally considered to promote pathological OA [3-5]. Proinflammatory cytokine mediators have been reported to contribute to OA pathogenesis by increasing cartilage degradation and inducing hyperalgesia via a number of direct and indirect actions. TNF $\alpha$ activates sensory neurons directly via its receptors and initiates a cascade of inflammatory reactions via the production of ILs [6,7]. IL-6 is reported to have a complex role in OA pathogenesis by initiating inflammatory responses such as the production of tissue inhibitors of metalloproteinase, and this may act to limit cartilage damage via negative feedback [8]. NGF is reportedly upregulated in human osteoarthritic chondrocytes and synovial fibroblasts, suggesting its important role in the pathology of OA [6,9]. Another report indicated that NGF antagonism is an important mediator of pain in OA because its antagonistic effect resulted in analgesia in a murine OA model [10].

Thus, investigations of the dynamic states of these cytokines should be conducted. Additionally, a previous study indicated a strong association between the radiographic images of knees with OA and with knee pain [11]. Under the hypothesis that relationships between these cytokines and clinical evaluations in OA patients are possible, the present study evaluated the association between proinflammatory cytokines in the synovial fluid from the knees of OA patients and radiographic severity and pain scale scores.

\section{Methods}

Our Institutional Review Board approved the present study. We obtained informed consent from each participating patient.

\section{Patient selection}

The present study included adult patients with knee pain who visited our facility for clinical consultation between August 2009 and March 2010. The present study consisted of patients with knee OA diagnosed using the American College of Rheumatology criteria for OA who had not received any prior treatment. Patients with clear clinical evidence of any involvement of trauma, prior treatment, or other orthopedic diseases including spinal disorders causing radicular pain in the legs were excluded. Patients diagnosed with rheumatoid arthritis based on physical examination and laboratory data were also excluded.

\section{Synovial fluid sampling and cytokine assay}

With the approval of patients, samples of synovial joint fluid were collected using a syringe and needle in our outpatient clinics by experienced orthopedic physicians. The samples of synovial fluid were aspirated directly without lavage and immediately stored at $-70^{\circ} \mathrm{C}$ until use. Freeze-thaw cycles were avoided. Cytokine quantification was performed using a double-antibody sandwich enzyme-linked immunosorbent assay (ELISA) for TNF $\alpha$, IL-6 (R\&D systems, Minneapolis, MN), and NGF (Boster Biological Tec., Wuhan, China) without dilution according to the manufacturers' protocols (centrifugation before use: for $15 \mathrm{~min}$ at 1,000 $\times g$ (TNF $\alpha$ and IL6) or for $20 \mathrm{~min}$ at $2,000 \times g(\mathrm{NGF}))$. The detection limits of the assays were $0.5 \mathrm{pg} / \mathrm{ml}$ for TNF $\alpha,<0.70 \mathrm{pg} / \mathrm{ml}$ for IL-6, and $<1 \mathrm{pg} / \mathrm{ml}$ for NGF. All samples were assessed in duplicate.

\section{Grading of $O A$ and pain evaluation}

Anteroposterior radiographs of the symptomatic knees were obtained. The X-ray beam was aimed at the lower pole of the patella and kept parallel to the joint surface. Radiographs were scored by experienced orthopedic surgeons using the Kellgren-Lawrence (KL) grading scale as follows: grade 1, doubtful narrowing of joint space and possible osteophytic lipping; grade 2, definite osteophytes and possible narrowing of joint space; grade 3, moderate multiple osteophytes, definite narrowing of joints space, some sclerosis, and possible deformity of bone contours; and grade 4, large osteophytes, marked narrowing of joint space, severe sclerosis, and definite deformity of bone contours [12]. The functional status and pain level of each patient were evaluated using the Western Ontario McMaster University Osteoarthritis Index (WOMAC) score [13]. The index consists of 3 subscales: pain, stiffness, and physical function. A higher score on the WOMAC scale represents poorer function or greater pain. The data were arranged according to the KL grade for each cytokine, and the correlations between the cytokines were analyzed. Correlations between the cytokine concentrations and WOMAC score were also analyzed.

\section{Statistical analysis}

Statistical differences between the 2 groups were determined using the Mann-Whitney $U$ test followed by Bonferroni's correction for multiple testing, and the statistical significance among the groups was determined using the Kruskal-Wallis test. The significance of correlations was determined by Spearman's rank correlation test (PASW statistics ver. 18 (SPSS Inc (IBM), Somers, $\mathrm{NY})$ ). A $p$ value $<0.05$ was considered significant.

\section{Results}

\section{Patient demographics}

Table 1 shows the patient demographics. Among the 50 patients enrolled in the present study, we could not 
Table 1 Patient Demographics

\begin{tabular}{ccccc}
\hline & \multicolumn{2}{c}{ Gender } & $\begin{array}{c}\text { Disease } \\
\text { duration } \\
\text { (months) }\end{array}$ & Total \\
\cline { 2 - 3 } & Male & Female & & \\
\hline $\begin{array}{c}\text { No. of Patients } \\
\text { Average age } \\
\text { (years) } \\
\text { KL grading }\end{array}$ & $22(21)$ & $28(26)$ & & $50(47)$ \\
1 & $69.6 \pm 7.3$ & $69.8 \pm 11.3$ & & $70.0 \pm 2.1$ \\
2 & 6 & 4 & $4.83 \pm 2.0$ & 10 \\
3 & 6 & 9 & $14.8 \pm 8.9$ & 15 \\
4 & 5 & 8 & $33.9 \pm 18.6$ & 13 \\
\hline
\end{tabular}

*No fluid was obtained from 3 patients (1 man and 2 women), and thus, the numbers in parenthesis indicate the effective numbers for the present study. ${ }^{*}$ Described as mean \pm SEM.

obtain any fluid from the knees of 3 patients with osteoarthritic knees classified as KL grade 4, and thus, we analyzed the other 47 samples. Disease duration increased as the KL scores increased.

\section{Concentrations of the proinflammatory cytokines}

Figure 1 shows the concentrations of proinflammatory cytokines in the synovial fluid of knee joints in relation to the radiographic findings for these joints. Measurable levels of TNF $\alpha$ and IL- 6 were detected in all samples, whereas NGF was not detectable in any of the samples
(CV value (\%): TNF $\alpha, 5.8 \pm 1.2$; IL-6, $4.2 \pm 0.18$; NGF: unable to be calculated).

The concentration of TNF $\alpha$ was significantly lower in KL grades 2 to 4 than in KL grade 1 (KL 1, $6.5 \pm 2.0$ $\mathrm{pg} / \mathrm{ml}$ (mean \pm S.E.); KL 2, $3.6 \pm 0.72 \mathrm{pg} / \mathrm{ml}(p=0.38$ vs. KL 1$)$; KL 3, $4.2 \pm 0.48 \mathrm{pg} / \mathrm{ml}(p=0.025$ vs. KL 1$)$; and $\mathrm{KL} 4,3.2 \pm 0.86 \mathrm{pg} / \mathrm{ml}(p=0.031$ vs. KL 1$)$ ) (Figure $1 \mathrm{~A})$. The IL-6 concentration was significantly lower in KL grades 3 and 4 than in KL grades 1 and 2 (KL 1 , $401.6 \pm 33.2 \mathrm{pg} / \mathrm{ml} ; \mathrm{KL} 2,292.6 \pm 42.2 \mathrm{pg} / \mathrm{ml} ; \mathrm{KL} 3$, $162.9 \pm 46.5 \mathrm{pg} / \mathrm{ml}$; and $\mathrm{KL} 4,78.6 \pm 62.8 \mathrm{pg} / \mathrm{ml})(p=$ 0.032 vs. KL $1 ; p=0.036$ vs. KL 2) (Figure 1B). NGF was not detected in any sample.

\section{Correlation between WOMAC score and cytokine concentration}

Figure 2 shows the correlations between the detectable cytokines and the WOMAC score. Group A shows TNF $\alpha$, and group B shows IL-6. TNF $\alpha$ exhibited a moderately significant positive correlation with the total WOMAC score (A-1) and with each subscale (pain (A-2), stiffness (A-3), and physical function (A-4) $(p<$ $0.01)$ ). IL-6 exhibited a moderately significant negative correlation only with stiffness (B-3) $(p<0.05)$, whereas it did not exhibit any significant correlation with the other factors. The precise statistical values are shown in Table 2.

\section{(A) $\mathrm{TNF} \alpha$}

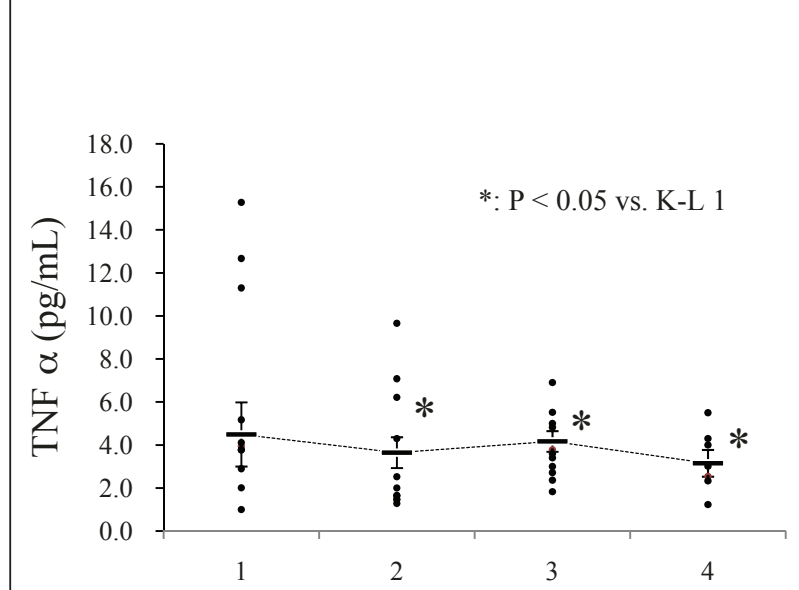

$\mathrm{K}-\mathrm{L}$ grade
(B) IL-6

*: $\mathrm{P}<0.05$ vs. K-L 1

$\dagger: \mathrm{P}<0.05$ vs. K-L 2

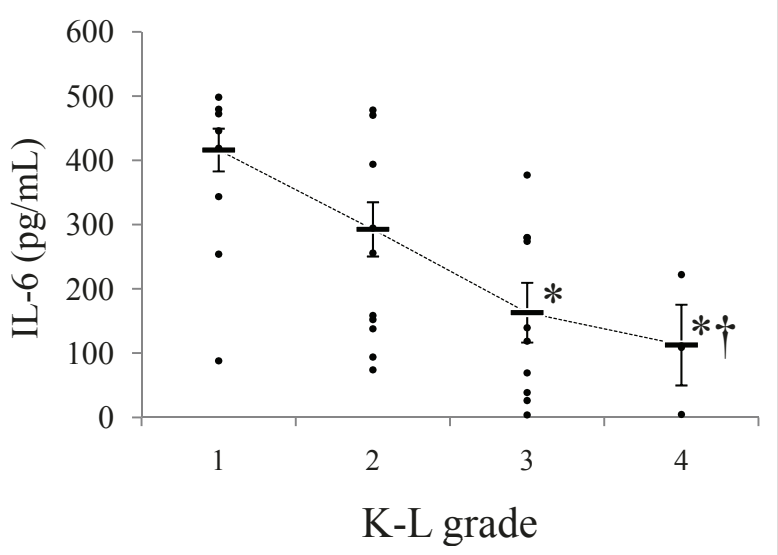

$($ Mean \pm SEM)

Figure 1 Concentrations of proinflammatory cytokines in the synovial fluid from the knee joints. (A) The concentration of TNF $\alpha$ exhibited no significant correlation with KL grading, although there was a tendency for increased TNF $\alpha$ concentrations at lower KL grades. (B) The concentration of IL-6 was significantly decreased in KL grades 3 and 4 compared with those in $\mathrm{KL}$ grades 1 and 2. NGF was undetectable in all patient samples: 


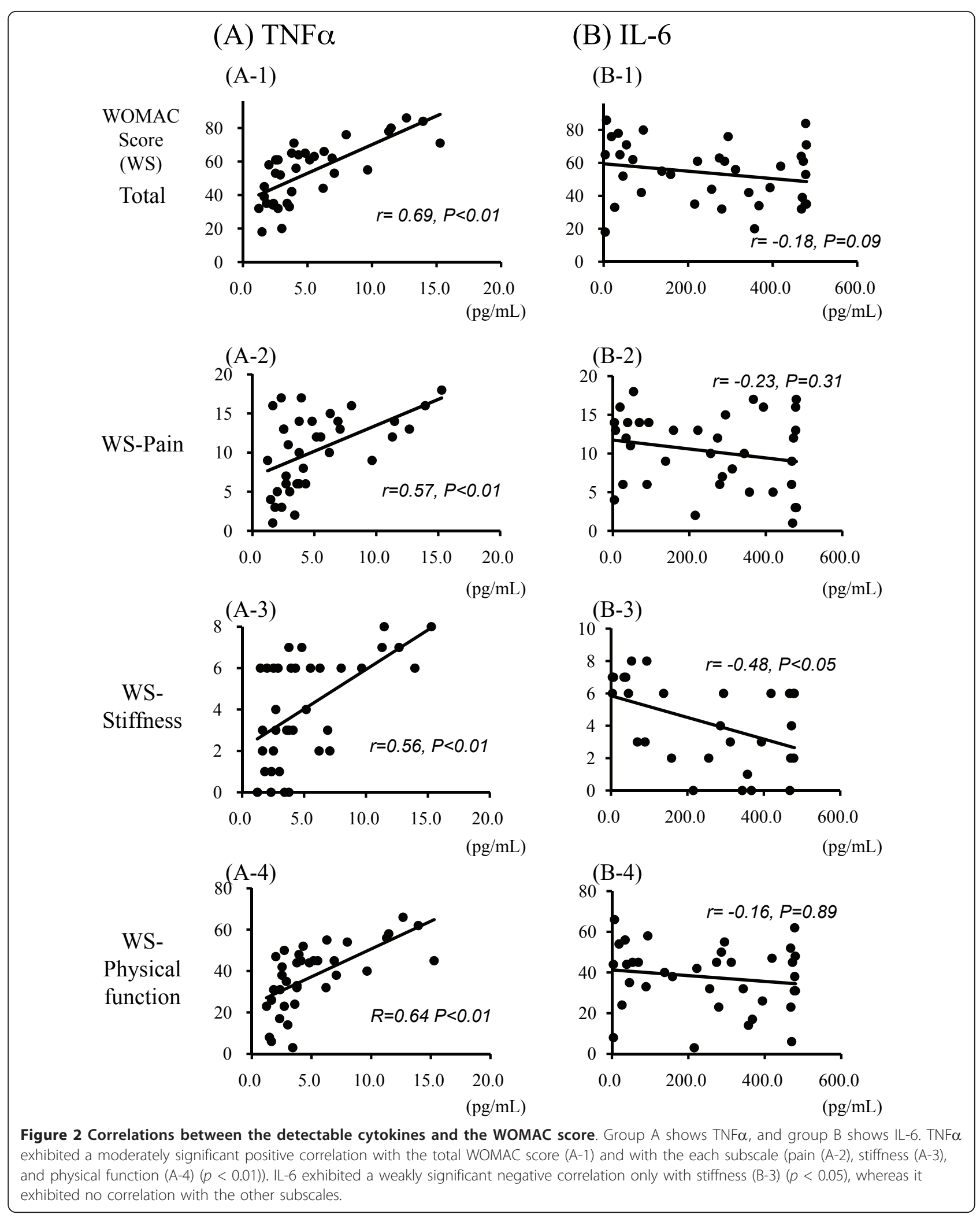


Table 2 Statistical data of Figure 2

\begin{tabular}{ccccc}
\hline & \multicolumn{2}{c}{ TNF $\boldsymbol{c}$} & \multicolumn{2}{c}{ IL-6 } \\
\cline { 2 - 5 } & $\boldsymbol{r}$ & $\boldsymbol{p}$ & $\boldsymbol{r}$ & $\boldsymbol{p}$ \\
\hline Total & 0.69 & 0.0023 & -0.18 & 0.09 \\
Pain & 0.57 & 0.0069 & -0.23 & 0.31 \\
Stiffness & 0.56 & 0.0054 & -0.48 & 0.039 \\
Physical function & 0.64 & 0.0038 & -0.16 & 0.89 \\
\hline
\end{tabular}

\section{Discussion}

The present study examined whether inflammation plays a substantial role in the development of pain in OA. We demonstrated that TNF $\alpha$ and IL- 6 were detectable in the synovial fluid sampled from the knees of OA patients, whereas NGF was undetectable. TNF $\alpha$ was not correlated with the KL grade, and IL- 6 had a relatively significant negative correlation with KL grading. Some differences were found between TNF $\alpha$ and IL-6 regarding their correlations with the WOMAC score and its subscales. TNF $\alpha$ exhibited a moderately significant correlation with the total score and its 3 subscales, whereas IL-6 exhibited a weakly significant negative correlation with the subscale of stiffness. The WOMAC scoring method used in the present study was translated from the English version, and thus, we believe that its validity is similar as that reported in a previous study in Asian OA patients [14].

\section{Evidence of proinflammatory cytokines in the synovial fluid samples}

The results of the present study are comparable with those of previous studies, which using a zymosaninduced mouse OA model, reported that TNF $\alpha$ is related to synovitis and that IL- 6 has a role in reducing cartilage destruction [15-18]. These studies add importance to the present findings that TNF $\alpha$ inhibition may improve the WOMAC score and that increased IL-6 activity in earlier phases of OA prevents cartilage destruction. Brenner et al performed a similar experiment using the synovial membranes and fluid from OA patients, and reported that TNF $\alpha$ was undetectable in their synovial fluid and that there were no correlations between IL-6 levels and WOMAC pain subscores [19]. Regarding TNF $\alpha$, some controversy exists among studies. Some previous studies reported low levels of TNF $\alpha$ in the synovial fluid of OA patients [20-22], whereas other studies including experiment models reported its detection [23-25]. The present study detected TNF $\alpha$ in the synovial fluid. These discrepancies may be attributable to the extremely low value of TNF $\alpha$ and the method of collecting and processing synovial fluid. However, we can suggest that TNF $\alpha$ is related to OA pathology and clinical evaluations based on the present findings, although additional investigations with greater numbers of samples are needed. Additionally, TNF $\alpha$ was also reported to not be regulated in the joints in late OA, and this is consistent with the finding of the present study [26].

As described in the Background section, NGF is considered an important factor in OA pathogenesis, and thus, it is important to discuss why NGF was not detected in the present study. We hypothesize that, excluding any technical errors, NGF production is insufficient for detection in the synovial fluid obtained from the knees of OA patients. According to a previous report, the mRNA expression of neurotrophins including NGF and its receptors was confirmed in the synovial fluid and tissues of patients with OA, whereas NGF mRNA expression was low [27]. Furthermore, NGF is a basic protein, and this is disadvantageous for its existence in the relatively acidic milieu of the synovial fluid [28]. Another study reported the diagnostic usefulness of biopsied tissue as opposed to the use of synovial fluid [26]. Thus, in addition to examining the synovial fluid, it may be important to investigate NGF expression in the subchondral tissue where inflammatory cytokines are reported to be produced [29]. Moreover, to investigate any correlation between proinflammatory cytokines including NGF, multivariable analysis among these cytokines should be performed in the future. Evaluating the levels of these cytokines in the synovial fluid from completely normal knees is important but also difficult for ethical reasons. Alternatively, we can evaluate the cytokine levels in the synovial fluid from injured knees such as those with anterior cruciate ligament (ACL) injuries; however, the data may not be useful because proinflammatory cytokine levels are elevated in response to any degradation or injury in the joint. However, we can partly infer their levels from previous studies. One study evaluating the cytokine levels in the knees of patients with chronic ACL deficiencies reported that TNFa concentrations were lower in injured knees than in normal knees, and the TNF $\alpha$ levels reported in that study were also low compared with those in the present study [30]. Because IL- 6 and TNF $\alpha$ levels are elevated in the early phase of knee injuries, it will be important to measure their levels in normal knees.

\section{Correlation between cytokine concentrations and $\mathrm{KL}$ grading}

A previous study indicated that the levels of TNF $\alpha$ in the synovial fluid were positively correlated with Larsen's radiographic grading of bone destruction in rheumatoid arthritis patients, whereas no correlation between the concentration of TNF $\alpha$ and Dahlgren's radiographic OA grade was found [31]. The report is consistent with some of the results of the present study regarding TNF $\alpha$ but not IL-6. The present study revealed that TNF $\alpha$ is clearly not correlated with joint 
degeneration as assessed by KL grading, whereas IL-6 is negatively correlated with KL grading, suggesting that IL-6 has an important role in OA progression. Generally, members of the IL family are reported to be related to the severity of cartilage destruction [32,33] The present study indicated that IL- 6 production might be increased in the early stage of joint destruction in OA patients. Other studies have reported that TNF $\alpha$ induces IL-6 upregulation, and thus, IL- 6 may still be correlated with OA progression [34-36]. Increased IL-6 activity has been reported to be associated with increased proteoglycan synthesis in articular cartilage in dogs with experimental ACL transaction [24], and thus, IL-6 production is highest in the early stages of joint injury.

Considering these reports, IL- 6 may be related to the formal pathogenesis of OA, suggesting that active cartilage destruction occurs at the greatest rate in earlier $\mathrm{KL}$ grades. In other words, late-stage KL grading may indicate the "burnt ruins" acquired after active inflammation where IL-6 is more directly involved than TNF $\alpha$.

\section{Correlation between cytokine concentrations and the WOMAC score}

The present study demonstrated that TNF $\alpha$ is significantly correlated with the WOMAC score including the subscores. However, IL- 6 was not correlated with the WOMAC score excluding the subscore of stiffness, which indicates that IL- 6 primarily affects the progress of the degeneration of joint cartilage in OA that leads to joint stiffness.

Furthermore, we found a correlation only with the subscore of stiffness, which can be derived from the constructive degradation of the cartilage, and we found no correlation with the subscore of pain. A previous paper reported a negative correlation between IL-6 activity and radiographic OA scoring in dog OA models [20], and this coincides with the results of the present study.

The present study has some limitations. First, we did not examine the gene expression of each cytokine. Variations in several genes that regulate inflammation have been reported to be associated with the differential expression of inflammatory mediators [37-39], some of which have been associated with OA pathology [40-44]. Thus, further studies including genetic investigations are needed, particularly for NGF. Second, the obscurity of $\mathrm{KL}$ grading, which is based on an unclear definition of the joint space findings, could have affected the results of the present study. Precise evaluation using more quantified grading systems such as the OARSI atlas should be performed in future studies. Third, we could not examine normal knees because it may be technically difficult and ethically improper to obtain control synovial fluid from intact knee joints. We should evaluate knees with other injuries or degradations in future studies. Last, we only examined the synovial fluid. It will be important to assess the serum levels of these cytokines and compare them with both the levels of cytokines in the synovial fluid and the grading scores.

\section{Conclusions}

The present study demonstrated that the concentrations of proinflammatory cytokines can be correlated with the KL grades and WOMAC scores of knee OA patients. TNF $\alpha$ did not have a significant correlation with the radiographic grading, while it did with the WOMAC scoring. IL-6 had a significant negative correlation with KL grading, and only a weakly significant correlation with the subscore of stiffness. These 2 cytokines were moderately correlated, and the results suggest that these cytokines play a role in the pathogenesis of synovitis in osteoarthritic knees in different ways. TNF $\alpha$ is correlated with pain, whereas IL-6 is correlated with joint function. NGF was undetectable in the synovial fluid, illustrating the need for differently designed experiments in future studies.

\section{Acknowledgements}

No funding was received for this research. None of the authors have any conflict of interest or disclosures to report in relation to this work.

\section{Author details}

${ }^{1}$ Department of Orthopaedic Surgery, Chiba Rosai Hospital, Chiba, Japan. ${ }^{2}$ Department of Orthopaedic Surgery, Seirei Sakura Citizen Hospital, Chiba, Japan. ${ }^{3}$ Department of Orthopaedic Surgery, Social Insurance Funabashi Central Hospital, Chiba, Japan. ${ }^{4}$ Department of Orthopaedic Surgery, Graduate School of Medicine, Chiba University, Chiba, Japan. ${ }^{5}$ Department of Orthopaedic Surgery, Chiba Social Insurance Hospital, Chiba, Japan. ${ }^{6}$ Department of Orthopaedic Surgery, Teikyo University Chiba Medical Center, Chiba, Japan.

\section{Authors' contributions}

SO designed and performed all the experiments, analyzed data, and drafted the paper. TK, TM, MM, Gl, GA, TI, EH, KY, MY, and YE harvested synovial fluid in their outpatient clinic and performed experiments. T, $K T$, and SO supervised the project and edited the manuscript. All authors contributed to data interpretation and have read and approved the final manuscript.

\section{Competing interests}

The authors declare that they have no competing interests.

Received: 21 November 2010 Accepted: 30 June 2011 Published: 30 June 2011

\section{References}

1. Todhunter PG, Kincaid SA, Todhunter RJ, Kammermann JR, Johnstone B, Baird AN, Hanson RR, Wright JM, Lin HC, Purohit RC: Immunohistochemical analysis of an equine model of synovitis-induced arthritis. Am J Vet Res 1996, 57:1080-1093.

2. Guccione AA, Felson DT, Anderson JJ, Anthony JM, Zhang Y, Wilson PW, Kelly-Hayes M, Wolf PA, Kreger BE, Kannel WB: The effects of specific medical conditions on the functional limitations of elders in the Framingham Study. Am J Public Health 1994, 84:351-358.

3. Fiorito S, Magrini L, Adrey J, Mailhe D, Brouty-Boye D: Inflammatory status and cartilage regenerative potential of synovial fibroblasts from patients with osteoarthritis and chondropathy. Rheumatology (Oxford) 2005, 44:164-171.

4. Pearle AD, Scanzello CR, George S, Mandl LA, DiCarlo EF, Peterson M, Sculco TP, Crow MK: Elevated high-sensitivity C-reactive protein levels 
are associated with local inflammatory findings in patients with osteoarthritis. Osteoarthr Cartilage 2007, 15:516-523.

5. Smith MD, Triantafillou S, Parker A, Youssef PP, Coleman M: Synovial membrane inflammation and cytokine production in patients with early osteoarthritis. J Rheumatol 1997, 24:365-371.

6. lannone F, De Bari C, Dell'Accio F, Covelli M, Patella V, Lo Bianco G, Lapadula G: Increased expression of nerve growth factor (NGF) and high affinity NGF receptor (p140 TrkA) in human osteoarthritic chondrocytes. Rheumatology (Oxford) 2002, 41:1413-1418.

7. Ohtori S, Takahashi K, Moriya H, Myers RR: TNFa and TNFa receptor type 1 upregulation in glia and neurons after peripheral nerve injury: studies in murine DRG and spinal cord. Spine 2004, 29:1082-1088.

8. Lotz M, Guerne PA: Interleukin-6 induces the synthesis of tissue inhibitor of metalloproteinases-1/erythroid potentiating activity (TIMP-1/EPA). $J$ Biol Chem 1991, 266:2017-2020

9. Manni L, Lundeberg T, Fiorito S, Bonini S, Vigneti E, Aloe L: Nerve growth factor release by human synovial fibroblasts prior to and following exposure to tumor necrosis factor-alpha, interleukin-1 beta and cholecystokinin-8: the possible role of NGF in the inflammatory response. Clin Exp Rheumatol 2003, 21:617-624.

10. Kay EMcNamee, Annika Burleigh, Luke LGompels, Marc Feldmann, Shelley JAllen, Richard OWilliams, David Dawbarn, Tonia LVincent, Julia Jnglis: Treatment of murine osteoarthritis with TrkAd5 reveals a pivotal role for nerve growth factor in non-inflammatory joint pain. Pain 2010, 149:386-92.

11. Neogi T, Felson D, Niu J, Nevitt M, Lewis CE, Aliabadi P, Sack B, Torner J, Bradley $L$, Zhang $Y$ : Association between radiographic features of knee osteoarthritis and pain: results from two cohort studies. BMJ 2009, 21:339.

12. Kellgren JH, Lawrence JS: Radiological assessment of osteo-arthrosis. Ann Rheum Dis 1957, 16:494-502.

13. Bellamy N, Buchanan WW, Goldsmith CH, Campbell J, Stitt LW: Validation study of WOMAC: a health status instrument for measuring clinically important patient relevant outcomes to antirheumatic drug therapy in patients with osteoarthritis of the hip or knee. J Rheumatol 1988, 15:1833-1840.

14. Thumboo J, Chew LH, Soh CH: Validation of the Western Ontario and Mcmaster University osteoarthritis index in Asians with osteoarthritis in Singapore. Osteoarthritis Cartilage 2001, 9:440-446.

15. Joosten LA, Helsen MM, Saxne T, van De Loo FA, Heinegard D, van Den Berg WB: IL-1 alpha beta blockade prevents cartilage and bone destruction in murine type II collagen-induced arthritis, whereas TNFalpha blockade only ameliorates joint inflammation. J Immunol 1999, 163:5049-5055.

16. van de Loo FA, Kuiper S, van Enckevort FH, Arntz OJ, van den Berg WB: Interleukin- 6 reduces cartilage destruction during experimental arthritis. A study in interleukin-6-deficient mice. Am J Pathol 1997, 151:177-191

17. Van Lent PL, Van De Loo FA, Holthuysen $A E$, Van Den Bersselaar LA Vermeer H, Van Den Berg WB: Major role for interleukin 1 but not for tumor necrosis factor in early cartilage damage in immune complex arthritis in mice. J Rheumatol 1995, 22:2250-2258.

18. van de Loo FA, Joosten LA, van Lent PL, Arntz OJ, van den Berg WB: Role of interleukin-1, tumor necrosis factor alpha, and interleukin-6 in cartilage proteoglycan metabolism and destruction. Effect of in situ blocking in murine antigen- and zymosan-induced arthritis. Arthritis Rheum 1995, 38:164-172.

19. Brenner SS, Klotz U, Alscher DM, Mais A, Lauer G, Schweer H, Seyberth HW, Fritz P, Bierbach : Osteoarthritis of the knee-clinical assessments and inflammatory markers. Osteoarthr Cartilage 2004, 12:469-475.

20. Hay CW, Chu Q, Budsberg SC, Clayton MK, Johnson KA: Synovial fluid interleukin 6, tumor necrosis factor, and nitric oxide values in dogs with osteoarthritis secondary to cranial cruciate ligament rupture. Am J Vet Res 1997, 58:1027-1032.

21. Holt I, Cooper RG, Denton J, Meager A, Hopkins S: Cytokine interrelationships and their association with disease activity in arthritis. $\mathrm{Br} J$ Rheumatol 1992, 31:725-733.

22. Futani H, Okayama A, Matsui K, Kashiwamura S, Sasaki T, Hada T, Nakanishi K, Tateishi H, Maruo S, Okamura H: Relation between interleukin-18 and PGE2 in synovial fluid of osteoarthritis: a potential therapeutic target of cartilage degradation. J Immunother 2002, 25:S61-64.
23. Westacott Cl, Whicher JT, Barnes IC, Thompson D, Swan AJ, Dieppe PA: Synovial fluid concentration of five different cytokines in rheumatic diseases. Ann Rheum Dis 1990, 49:676-681.

24. Venn G, Nietfeld JJ, Duits AJ, Brennan FM, Arner E, Covington M, Billingham ME, Hardingham TE: Elevated synovial fluid levels of interleukin-6 and tumor necrosis factor associated with early experimental canine osteoarthritis. Arthritis Rheum 1993, 36:819-826.

25. Smith MD, Triantafillou S, Parker A, Youssef PP, Coleman M: Synovial membrane inflammation and cytokine production in patients with early osteoarthritis. J Rheumatol 1997, 24:365-371.

26. Johnson SJ, Freemont AJ: A 10 year retrospective comparison of the diagnostic usefulness of synovial fluid and synovial biopsy examination. J Clin Pathol 2001, 54:605-607.

27. Barthel C, Yeremenko N, Jacobs R, Schmidt RE, Bernateck M, Zeidler $H$ Tak PP, Baeten D, Rihl M: Nerve growth factor and receptor expression in rheumatoid arthritis and spondyloarthritis. Arthritis Res Ther 2009, 11:R82.

28. Goldstein LD, Reynolds CP, Perez-Polo JR: Isolation of human nerve growth factor from placental tissue. Neurochem Res 1978, 3:175-183.

29. Hulejová H, Baresová V, Klézl Z, Polanská M, Adam M, Senolt L: Increased level of cytokines and matrix metalloproteinases in osteoarthritic subchondral bone. Cytokine 2007, 38:151-156.

30. Marks PH, Donaldson ML: Inflammatory cytokine profiles associated with chondral damage in the anterior cruciate ligament-deficient knee. Arthroscopy 2005, 21:1342-1347.

31. Neidel J, Schulze M, Lindschau J: Association between degree of boneerosion and synovial fluid-levels of tumor necrosis factor alpha in the kneejoints of patients with rheumatoid arthritis. Inflamm Res 1995, 44:217-221.

32. Long D, Blake S, Song XY, Lark M, Loeser RF: Human articular chondrocytes produce IL-7 and respond to IL-7 with increased production of matrix metalloproteinase-13. Arthritis Res Ther 2008, 10:R23.

33. Attur M, Wang H, Kraus BV, Bukowski FJ, Aziz N, Krasnokutsky S, Samuels J, Greenberg J, McDaniel G, Abramson BS, Kornman SK: Radiographic severity of knee osteoarthritis is conditional on interleukin-1 receptor antagonist gene variations. Ann Rheum Dis 2010, 69:856-861.

34. Gauldie J, Richards C, Harnish D, Lansdorp P, Baumann H: Interferon beta 2/B-cell stimulatory factor type 2 shares identity with monocyte-derived hepatocyte-stimulating factor and regulates the major acute phase protein response in liver cells. Proc Natl Acad Sci USA 1987, 84:7251-7255.

35. Lee KM, Jeon SM, Cho HJ: Tumor necrosis factor receptor 1 induces interleukin-6 upregulation through NF-kappaB in a rat neuropathic pain model. Eur J Pain 2009, 13:794-806.

36. Gauldie J, Richards C, Harnish D, Lansdorp P, Baumann H: Mechanisms of tumor necrosis factor-alpha-induced interleukin-6 synthesis in glioma cells. J Neuroinflamm 2010, 7:16.

37. Kahraman S, Yilmaz R, Arici M, Altun B, Erdem Y, Yasavul U, Turgan C: IL-10 genotype predicts serum levels of adhesion molecules, inflammation and atherosclerosis in hemodialysis patients. J Nephrol 2006, 19:50-56.

38. Reiner AP, Wurfel MM, Lange LA, Carlson CS, Nord AS, Carty CL, Rieder MJ, Desmarais C, Jenny NS, Iribarren C, Walston JD, Williams OD, Nickerson DA Jarvik GP: Polymorphisms of the IL1-receptor antagonist gene (IL1RN) are associated with multiple markers of systemic inflammation. Arterioscler Thromb Vasc Biol 2008, 28:1407-1412.

39. Rogus J, Beck JD, Offenbacher S, Huttner K, lacoviello L, Latella MC, de Gaetano M, Wang HY, Kornman KS, Duff GW: IL1B gene promoter haplotype pairs predict clinical levels of interleukin-1 beta and C-reactive protein. Hum Genet 2008, 123:387-398.

40. Loughlin J, Dowling B, Mustafa Z, Chapman K: Association of the interleukin-1 gene cluster on chromosome 2q13 with knee osteoarthritis. Arthritis Rheum 2002, 46:1519-1527.

41. Moos V, Rudwaleit M, Herzog V, Höhlig K, Sieper J, Müller B: Association of genotypes affecting the expression of interleukin-1 beta or interleukin-1 receptor antagonist with osteoarthritis. Arthritis Rheum 2000, 43:2417-2422.

42. Riyazi N, Kurreeman FA, Huizinga TW, Dekker FW, Stoeken-Riisbergen G, Kloppenburg M: The role of interleukin 10 promoter polymorphisms in the susceptibility of distal interphalangeal osteoarthritis. J Rheumatol 2005, 32:1571-1575.

43. Smith AJ, Keen LJ, Billingham MJ, Perry MJ, Elson CJ, Kirwan JR, Sims JE, Doherty M, Spector TD, Bidwell JL: Extended haplotypes and linkage disequilibrium in the IL1R1-IL1A-IL1B-IL1RN gene cluster: association with knee osteoarthritis. Genes Immun 2004, 5:451-460. 
44. Valdes AM, Van Oene M, Hart DJ, Surdulescu GL, Loughlin J, Doherty M, Spector TD: Reproducible genetic associations between candidate genes and clinical knee osteoarthritis in men and women. Arthritis Rheum 2006, 54:533-539.

\section{Pre-publication history}

The pre-publication history for this paper can be accessed here: http://www.biomedcentral.com/1471-2474/12/144/prepub

doi:10.1186/1471-2474-12-144

Cite this article as: Orita et al:: Associations between proinflammatory cytokines in the synovial fluid and radiographic grading and painrelated scores in 47 consecutive patients with osteoarthritis of the knee. BMC Musculoskeletal Disorders 2011 12:144.

Submit your next manuscript to BioMed Central and take full advantage of:

- Convenient online submission

- Thorough peer review

- No space constraints or color figure charges

- Immediate publication on acceptance

- Inclusion in PubMed, CAS, Scopus and Google Scholar

- Research which is freely available for redistribution

Submit your manuscript at www.biomedcentral.com/submit 